\title{
Glycyrrhizic Acid Promotes M1 Macrophage Polarization in Murine Bone Marrow-Derived Macrophages Associated with the Activation of JNK and NF- $\kappa$ B
}

\author{
Yulong Mao, Baikui Wang, Xin Xu, Wei Du, Weifen Li, and Youming Wang \\ Key Laboratory of Animal Molecular Nutrition of Education of Ministry, College of Animal Sciences, Zhejiang University, \\ 866 Yu Hang Tang Road, Hangzhou, Zhejiang 310058, China \\ Correspondence should be addressed to Weifen Li; weifenli@zju.edu.cn and Youming Wang; ymwang@zju.edu.cn
}

Received 7 July 2015; Revised 10 October 2015; Accepted 15 October 2015

Academic Editor: Yona Keisari

Copyright (c) 2015 Yulong Mao et al. This is an open access article distributed under the Creative Commons Attribution License, which permits unrestricted use, distribution, and reproduction in any medium, provided the original work is properly cited.

\begin{abstract}
The roots and rhizomes of Glycyrrhiza species (licorice) have been widely used as natural sweeteners and herbal medicines. The aim of this study is to investigate the effect of glycyrrhizic acid (GA) from licorice on macrophage polarization. Both phenotypic and functional activities of murine bone marrow-derived macrophages (BMDMs) treated by GA were assessed. Our results showed that GA obviously increased the cell surface expression of CD80, CD86, and MHCII molecules. Meanwhile, GA upregulated the expression of CCR7 and the production of TNF- $\alpha$, IL-12, IL-6, and NO (the markers of classically activated (M1) macrophages), whereas it downregulated the expression of MR, Yml, and Arg1 (the markers of alternatively activated (M2) macrophage). The functional tests showed that GA dramatically enhanced the uptake of FITC-dextran and E. coli K88 by BMDMs and decreased the intracellular survival of E. coli K88 and S. typhimurium. Moreover, we demonstrated that JNK and NF- $\kappa$ B activation are required for GA-induced NO and M1-related cytokines production, while ERK1/2 pathway exhibits a regulatory effect via induction of IL-10. Together, these findings indicated that GA promoted polarization of M1 macrophages and enhanced its phagocytosis and bactericidal capacity. The results expanded our knowledge about the role of GA in macrophage polarization.
\end{abstract}

\section{Introduction}

Licorice, the root of Glycyrrhiza uralensis, is a wellrecognized, natural sweetener and used as a traditional herbal medicine for the treatment of various pathological conditions, including allergies, liver disease, gastric ulcers, and adrenal insufficiency $[1,2]$. A number of components have been isolated from licorice, including triterpene saponins, flavonoids, polysaccharides, and other substances [3]. Glycyrrhizic acid (GA), a major biologically active constituent of licorice root accounting for the sweet taste, is a triterpene glycoside containing one molecule of 18-glycyrrhetinic acid and two molecules of glucuronic acid [4]. So far, GA has been reported to have a variety of pharmacological activities like antiviral, antitumor, anti-inflammatory, and antioxidative activities [5-8]. It has been shown that GA can promote function of endothelial system and secretion of cytokines such as interleukin- (IL-) 1 and interferon- (IFN-) $\alpha$ [9], induce maturation of dendritic cells (DCs) [10], increase T cells proliferation and production of IL-2 and IFN- $\gamma[11,12]$, augment natural killer (NK) cell activity [13], enhance phagocytic capacity and nitric oxide (NO) production in activated macrophages [14], and downregulate the production of IL-8 and eotaxin-1 in human lung fibroblast cells [4]. These studies indicated that GA may serve as an immune modulator which precisely regulates the cellular immunity.

Macrophages have long been considered as important effector cells that play a key role in host defense and homeostasis $[15,16]$. Depending on the microenvironment, macrophages can acquire distinct morphological and functional properties. Two extremes in the spectrum of macrophage phenotypes are often referred to as classically activated macrophages (or M1) and alternatively activated macrophages (or M2) [17, 18]. The M1 phenotype is polarized by Thl cytokines such as IFN- $\gamma$ and is characterized by high capacity to present antigen, high levels of inflammatory 
cytokines (TNF- $\alpha$, IL-12, IL-6) secretion and increased levels of NO production, enhanced capacity to kill intracellular pathogens and tumor cells, and promotion of polarized Th1 and Th17 responses $[15,19,20]$. In contrast, M2 macrophages are polarized by Th2 cytokines such as IL- 4 and IL-13 and are characterized by minimal production of inflammatory molecules and increased expression of mannose receptor (MR), chitinase-like Yml, found in inflammatory zone1 (FIZZ1), and arginase-1 (Arg1). M2 cells are associated with anti-inflammatory and homeostatic functions linked to wound healing, tissue remodeling and repair, scavenge debris, and participation in polarized Th2 reactions [21, 22]. Generally, M1 macrophages are considered proinflammatory cells, whereas M2 macrophages are anti-inflammatory.

However, there is limited information about how GA regulates the phenotype of macrophages. In the present study, we investigated the effect of GA on the polarization of murine bone marrow-derived macrophages (BMDMs) and found that GA promotes M1, rather than M2 macrophage polarization with enhanced phagocytosis and bacterial killing capacity. We further demonstrated that GA-mediated macrophage polarization involves activation of mitogen-activated protein kinases (MAPKs) and nuclear factor- $\kappa \mathrm{B}(\mathrm{NF}-\kappa \mathrm{B})$ pathways.

\section{Materials and Methods}

2.1. Reagents. Dulbecco's modified eagle's medium (DMEM), LPS (Escherichia coli 0111:B4), FITC-dextran (40,000 Da), and glycyrrhizic acid (GA) were purchased from Sigma Chemical Co. (St. Louis, MO, USA). There was no detectable endotoxin $(<0.10$ endotoxin units $/ \mathrm{mL})$ in the GA samples, as determined by Endospecy. Recombinant moues IFN- $\gamma$, MCSF, and IL-4 were obtained from PeproTech Inc. (Rocky Hill, NJ, USA). Anti-mouse antibodies FITC-F4/80, -CD80, -CD86, -MR and PE-MHCII, and -CCR7 as well as anti-NF$\kappa \mathrm{B}$ p65 were obtained from Biolegend (San Diego, CA, USA). The ELISA kits for TNF- $\alpha$, IL-6, IL-10, and IL-12p70 were obtained from eBioscience (San Diego, CA, USA). Antibodies against $\beta$-actin, iNOS, phospho-JNK, JNK, phospho-p38 MAPK, p38 MAPK, I $\kappa \mathrm{B} \alpha$, LaminB1, and HRP-conjugated anti-mouse and anti-goat IgG were purchased from Santa Cruz Biotech (Santa Cruz, CA, USA), and phospho-ERK1/2, anti-ERK1/2, phospho-STAT1, and anti-STAT1 antibodies were obtained from BD Pharmingen (San Jose, CA, USA). Inhibitors BAY 11-7082, SP600125, SB203580, and U0126 were purchased from Beyotime Biotechnology (Haimen, Jiangsu, China).

2.2. Animals. C57BL/6 mice (6 8 weeks old) were purchased from Slac Animal Inc. (Shanghai, China) and reared in Experimental Animal Center of Zhejiang University. All experimental protocols for animal studies were approved by the Institutional Animal Care and Use Committee of Zhejiang University.

2.3. Preparation of Bone Marrow-Derived Macrophages (BMDMs). The preparation of BMDMs was modified from a previously described method [23]. Briefly, mice were killed by cervical dislocation and the femur and tibia of the hind legs were dissected and bone marrow cavities were flushed with $5 \mathrm{~mL}$ cold, sterile phosphate buffered saline (PBS). After lysing red blood cells, the bone marrow cells were washed, resuspended, and differentiated into BMDMs in DMEM with $10 \% \mathrm{FBS}, 10 \mathrm{ng} / \mathrm{mL} \mathrm{M}-\mathrm{CSF}, 100 \mu \mathrm{g} / \mathrm{mL}$ streptomycin, and $100 \mathrm{U} / \mathrm{mL}$ penicillin. Six days after initial BMDMs cell culture, the purity of $\mathrm{F} 4 / 80^{+}$cells was $>90 \%$, as determined by flow cytometry (FACS).

2.4. Cytotoxicity Assay. Monolayers of BMDMs in 96-well microplate were cultured in DMEM supplemented with $10 \%$ FBS and incubated with GA $(0 \sim 800 \mu \mathrm{g} / \mathrm{mL})$ for $48 \mathrm{~h}$. The medium was replaced with fresh DMEM containing $0.5 \mathrm{mg} / \mathrm{mL}$ MTT. After $4 \mathrm{~h}$ of incubation, the supernatant was removed and the precipitation was dissolved with DMSO. Finally, the optical density was measured using SpectraMax M5 (MD) at $\mathrm{OD}_{570}$ [24].

Lactate dehydrogenase (LDH) release from damaged cells was determined $48 \mathrm{~h}$ after treatment with PBS (Blank control), GA $(100 \mu \mathrm{g} / \mathrm{mL})$, IFN- $\gamma(15 \mathrm{ng} / \mathrm{mL})+$ LPS $(15 \mathrm{ng} / \mathrm{mL})$ (M1-positive control), and IL-4 (20 ng/mL) (M2-positive control). LDH activity in the culture supernatant was measured as previously described [25].

2.5. Flow Cytometry Analysis. To detect cell surface expression of CC chemokine receptor 7 (CCR7), MR, CD80, CD86, and MHC class II (MHCII), cells from different treatment groups were, respectively, collected and stained with antibodies against CCR7, MR, CD80, CD86, and MHCII for $30 \mathrm{~min}$ at $4^{\circ} \mathrm{C}$ and then washed twice with PBS and analyzed in a FACScalibur flow cytometer (Becton-Dickinson).

2.6. Total RNA Isolation and Real-Time PCR. Total RNA isolated from BMDMs (RNAiso plus, TAKARA) was reversetranscribed using PrimeScript II 1st Strand cDNA Synthesis Kit (TAKARA). Real-time PCR was performed using SYBR Premix Ex Taq II (TAKARA) and the ABI 7500 real-time PCR system (Applied Biosystems). The following primers were used: TNF- $\alpha$ forward $5^{\prime}$-CCCTCACACTCAGATCATCTTCT- $3^{\prime}$ and reverse $5^{\prime}$-GCTACGACGTGGGCTACAG- $3^{\prime}$; IL12 p 40 forward $5^{\prime}$-CCCATTCCTACTTCTCCCTCAA- $3^{\prime}$ and reverse $5^{\prime}$-CCTCCTCTGTCTCCTTCATCTT- $3^{\prime}$; IL- 6 forward $5^{\prime}$-TAGTCCTTCCTACCCCAATTTCC- $3^{\prime}$ and reverse $5^{\prime}$-TTGGTCCTTAGCCACTCCTTC- $3^{\prime}$; Yml forward $5^{\prime}$ ACTCCTCAGAACCGTCAGAT-3' and reverse $5^{\prime}$-GTAGCAGCCTTGGAATGCTTT-3' ; MR forward $5^{\prime}$-GACGCTCTAAGTGCCATCTC- $3^{\prime}$ and reverse $5^{\prime}$-ATAACTCTGTGCCCTTGATTCC- $3^{\prime}$; FIZZ1 forward $5^{\prime}$-TCGTGGAGAATAAGGTCAAGGAA-3' and reverse $5^{\prime}$-CGAGTAAGCACAGGCAGTTG- $3^{\prime}$; iNOS forward $5^{\prime}$-CTCACCTACTTCCTGGACATTAC- $3^{\prime}$ and reverse $5^{\prime}$-CAATCTCTGCCTATCCGTCTC-3'; Arg1 forward 5' -GCCTTTGTTGATGTCCCTAATGA- $3^{\prime}$ and reverse $5^{\prime}$-CCACACTGACTCTTCCATTCTTC-3'; IL-10 forward $5^{\prime}$-GCTCTACTGACTGGCATGAG- $3^{\prime}$ and reverse $5^{\prime}$-CGCAGCTCTAGGAGCATGT$3^{\prime}$; $\beta$-actin forward $5^{\prime}$-CGTTGACATCCGTAAAGACC- $3^{\prime}$ and reverse $5^{\prime}$-AACAGTCCGCCTAGAAGCAC- $3^{\prime}$. Fold changes were calculated after normalizing the change in 
expression of the gene of interest to the housekeeping gene $\beta$-actin using the threshold cycle values.

2.7. Cytokine Assay. Levels of TNF- $\alpha$, IL-12p70, IL-6, and IL-10 in the culture supernatants were quantified using a sandwich ELISA kit (eBioscience) as per the manufacturer's instructions.

2.8. Western Blotting Analysis. Total cell lysates were prepared as previously described [26]. Nuclear and cytosolic extracts were fractionated using a Nuclear and Cytoplasmic Protein Extraction Kit (Beyotime Biotechnology) according to the manufacturer's instructions. Equal amounts of proteins from each sample were subjected to SDS-PAGE followed by transfer of proteins to nitrocellulose membranes. Membranes were blocked in no protein blocking solution (Sangon Biotech) and incubated with a primary antibody overnight at $4^{\circ} \mathrm{C}$. After washing with TBST, membranes were incubated with secondary antibody linked to HRP. The blots were then developed with an ECL detection system as per the manufacturer's instructions.

2.9. Nitrite Generation Assay. Nitrite accumulation in culture supernatant was measured by the Griess method [27]. Cell-free culture supernatants were mixed with $100 \mu \mathrm{L}$ of $1 \%$ sulfanilamide, $0.1 \% \mathrm{~N}$-(1-naphthyl-) ethyl-enediamine dihydrochloride, and $2.5 \%$ phosphoric acid. The absorbency was read within $5 \mathrm{~min}$ at $550 \mathrm{~nm}$ and actual concentration calculated using a standard curve with serial dilutions of sodium nitrite.

2.10. Phagocytosis Assay. To analyze the phagocytic activity of macrophages, BMDMs were pretreated with GA $(100 \mu \mathrm{g} / \mathrm{mL})$ for $12 \mathrm{~h}$ and then incubated with FITC-dextran $(1 \mathrm{mg} / \mathrm{mL})$ at $37^{\circ} \mathrm{C}$ for $1 \mathrm{~h}$. After incubation, the cells were washed twice with PBS and the percentage and mean fluorescence intensity (MFI) of intracellular FITC-dextran were determined by FACS.

2.11. Bacteria Killing Analysis. To determine the bactericidal function of macrophages, BMDMs were seeded at $2 \times 10^{5}$ cells/well in 24-well culture plates (Corning) and pretreated with GA $(100 \mu \mathrm{g} / \mathrm{mL})$ for $12 \mathrm{~h}$, and then cells were washed and incubated with $1 \times 10^{7}$ Escherichia coli (E. coli) (stain K88) or $2 \times 10^{7}$ Salmonella typhimurium (S. typhimurium) (strain CMCC-50115) for $1 \mathrm{~h}$ at $37^{\circ} \mathrm{C}$ to allow bacterial adhesion and colonization. Thereafter, cells were thoroughly washed with PBS and incubated for $0 \mathrm{~h}$ or $24 \mathrm{~h}$ in DMEM containing gentamicin $(25 \mu \mathrm{g} / \mathrm{mL})$. Finally, cell lysate from BMDMs containing intracellular bacteria was serially diluted with PBS and spread onto LB agar plates to determine bacterial viability.

2.12. Statistical Analysis. Results are presented as mean \pm SD of three independent experiments. Statistical analyses were performed using two-tailed Student's $t$-test. Values of $P<$ 0.05 were considered significant.

\section{Results}

3.1. Determination of the Noncytotoxic Dose of GA in BMDMs. We evaluated the cytotoxicity of GA ranging from 12.5 to $800 \mu \mathrm{g} / \mathrm{mL}$ on BMDMs and found the optimal viability was $100 \mu \mathrm{g} / \mathrm{mL}$, showing 97.44\% survival (Figure 1(a)). Moreover, we confirmed cell damage of each treatment used in following experiments by measuring the release of the cytosolic marker LDH. Treatment with GA $(100 \mu \mathrm{g} / \mathrm{mL})$ and IFN- $\gamma(15 \mathrm{ng} / \mathrm{mL})$ + LPS $(15 \mathrm{ng} / \mathrm{mL})$ for $48 \mathrm{~h}$ showed no significant difference of $\mathrm{LDH}$ release when compared with the control groups, while IL-4 $(20 \mathrm{ng} / \mathrm{mL})$ significantly decreased LDH release (Figure 1(b)). Therefore, $100 \mu \mathrm{g} / \mathrm{mL} \mathrm{GA}$ was used for the next experiments.

3.2. The Activation Profiles of BMDMs Treated with GA. Activated macrophages are able to present antigen to $\mathrm{T}$ cells and induce an effective $\mathrm{T}$ cell response [28]. One of the defining characteristics of an efficient antigen-presenting cell is the expression of MHCII and costimulatory molecules like CD80 and CD86. To investigate whether GA regulates the expression of such molecules on macrophages, BMDMs were incubated with GA $(100 \mu \mathrm{g} / \mathrm{mL})$ for $48 \mathrm{~h}$. As shown in Figure 2, the percentage of CD80, CD86, and MHCII expression after GA treatment was upregulated from $9.86 \%$, $90.84 \%$, and $26.66 \%$ to $22.59 \%, 97.97 \%$, and $63.16 \%$, respectively. Meanwhile, the intensity of expression of all three molecules was significantly enhanced by the GA treatment. These data demonstrated that the BMDMs activation was effectively induced by the dose of GA $(100 \mu \mathrm{g} / \mathrm{mL})$.

3.3. GA Promotes M1, rather than M2 Macrophages Polarization of BMDMs. We further studied the effect of GA on BMDMs polarization. First, cell images were captured after $48 \mathrm{~h}$ of treatment. BMDMs in the control groups were oval or irregularly shaped cells with clear cell borders, while the GA-treated cells exhibited more pits and vacuoles and closely attached to the button with less distinct cell borders. As shown in Figure 3, the morphological characteristics of the GA-treated cells were more similar to those in M1-positive groups. To confirm whether GA mediates M1 macrophages polarization of BMDMs, we examined the expressions of M1- and M2-associated markers (Figure 4). FACS analysis demonstrated that GA markedly increased the expression of M1 surface marker CCR7, from $6.5 \%$ to $20.35 \%$, whereas it decreased the expression of M2 surface marker MR, from $12.86 \%$ to $10.75 \%$ (Figure $4(\mathrm{a})$ ). Furthermore, GA upregulated the expression of M1-associated cytokines, such as TNF- $\alpha$, IL12 , and IL-6, at both the mRNA and protein levels; however, GA downregulated the mRNA expression of M2 markers, such as Yml and MR (Figures 4(b) and 4(c)). These results indicated that GA promotes typical M1 activation phenotype in BMDMs.

3.4. GA Induces NO Synthesis in BMDMs. M1 macrophages produce inducible nitric oxide synthase (iNOS) that enables the cell to kill intracellular pathogens through the production of NO, while M2 macrophages counteract iNOS activity by 


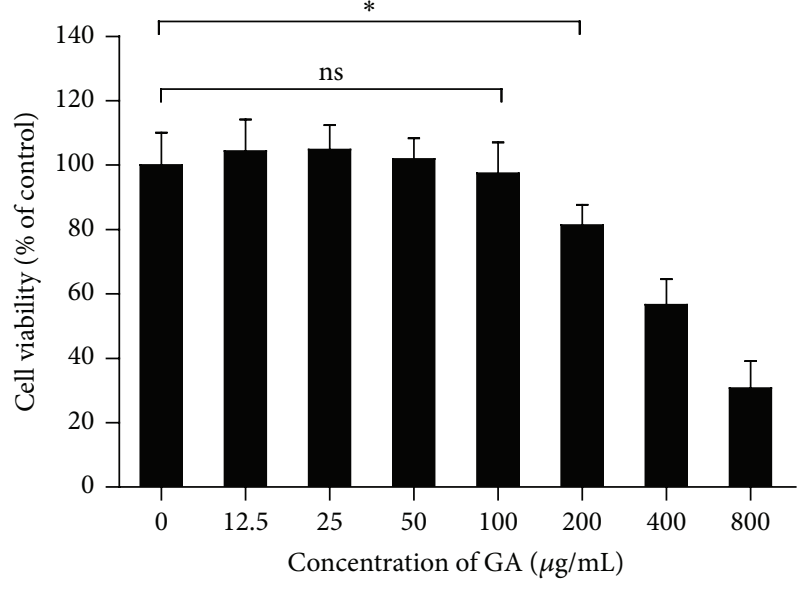

(a)

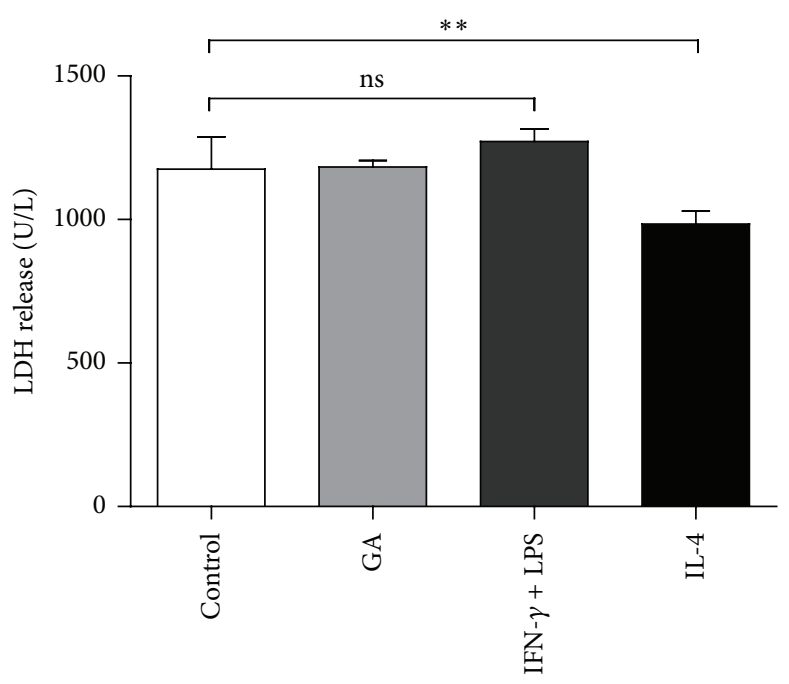

(b)

FIgURE 1: Determination of the noncytotoxic dose of GA. (a) BMDMs were incubated with GA at range from 0 to $800 \mu \mathrm{g} / \mathrm{mL}$ for $48 \mathrm{~h}$. Cell viability was determined by MTT method. The results are expressed as the percentage of viable cells and represent mean \pm SD of eight samples. (b) Cell death was confirmed by measuring the release of the cytosolic marker LDH. BMDMs were treated with PBS, GA (100 $\mu \mathrm{g} / \mathrm{mL})$, IFN- $\gamma$ $(15 \mathrm{ng} / \mathrm{mL})+$ LPS $(15 \mathrm{ng} / \mathrm{mL})$, and IL-4 $(20 \mathrm{ng} / \mathrm{mL})$ for $48 \mathrm{~h}$, and LDH activity in the supernatant was measured as described in Section 2 . ${ }^{*} P<0.05,{ }^{* *} P<0.01$ (t-test).
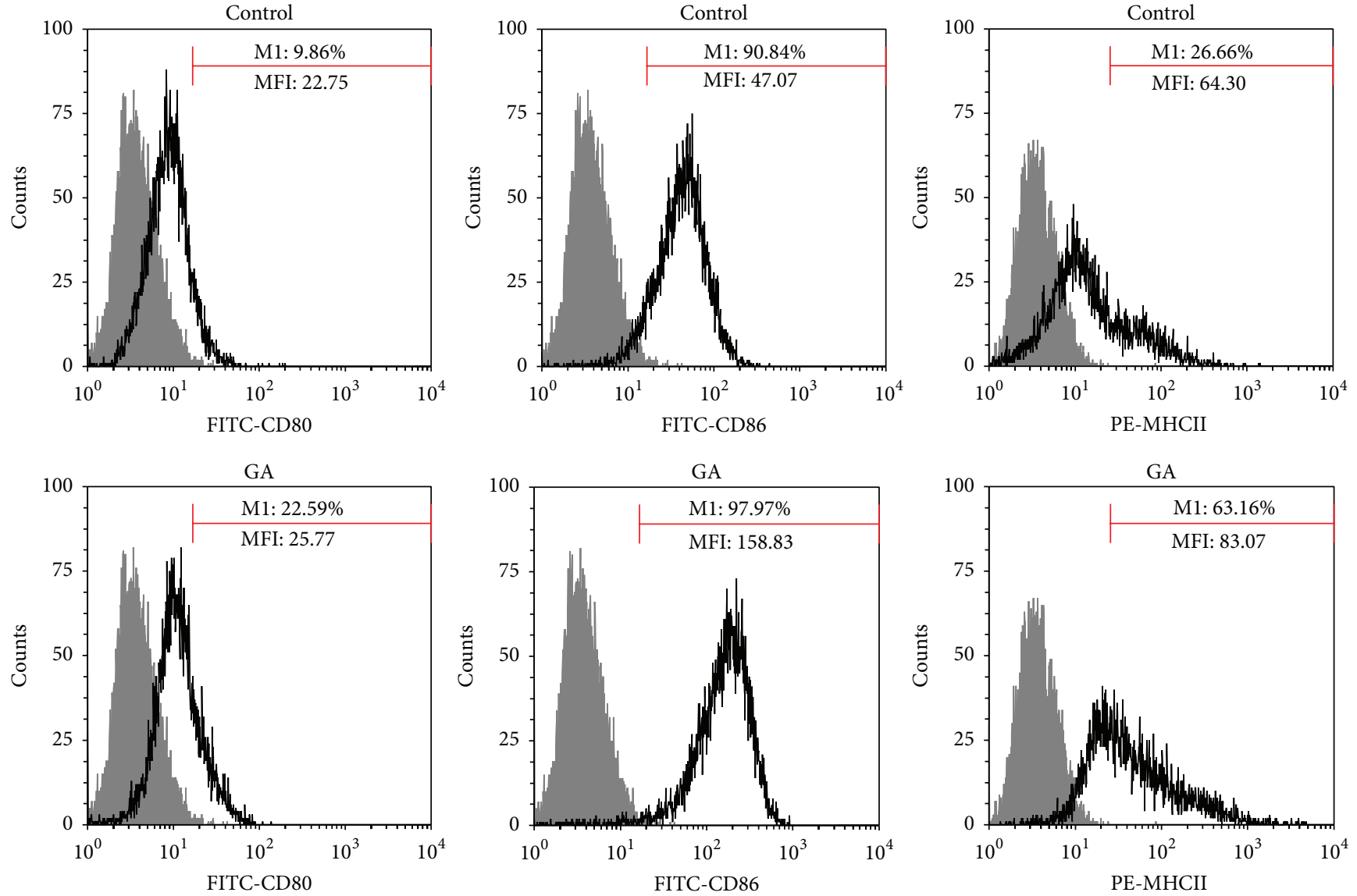

FIgURE 2: The activation profiles of BMDMs treated with GA. BMDMs were treated with GA $(100 \mu \mathrm{g} / \mathrm{mL})$ for $48 \mathrm{~h}$. Cells were harvested and stained with antibodies to CD80, CD86, and MHCII. Expressions of the surface molecules were analyzed by FACS and displayed, respectively, by the single parameter diagram. The values shown in the profiles were the gated $\%$ and the MFI. Results are representative of three independent experiments. 

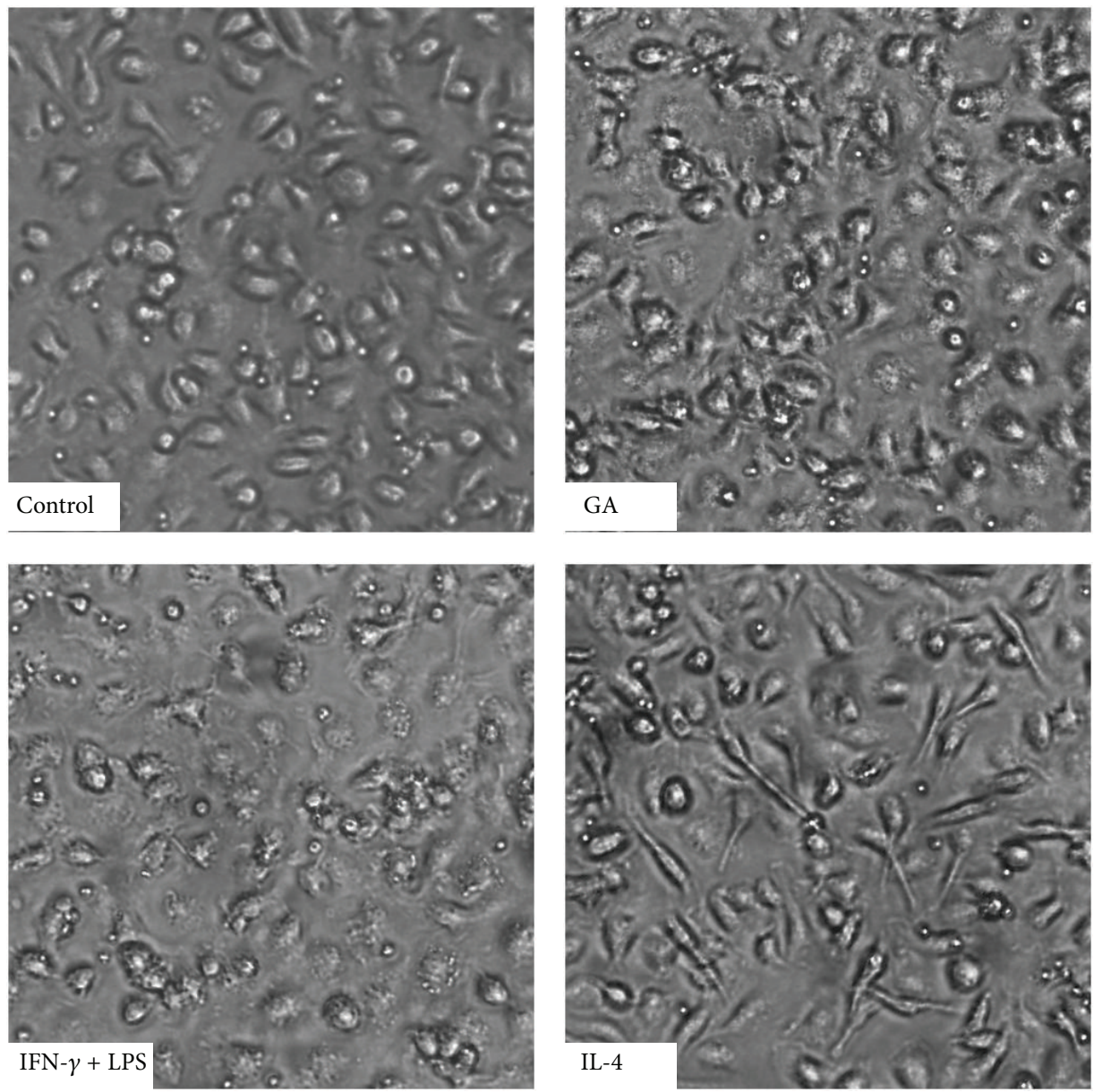

FIGURE 3: Effect of GA on morphological characteristics of BMDMs. BMDMs were treated with PBS, GA $(100 \mu \mathrm{g} / \mathrm{mL}), \mathrm{IFN}-\gamma(15 \mathrm{ng} / \mathrm{mL})+$ LPS $(15 \mathrm{ng} / \mathrm{mL})$, and IL-4 $(20 \mathrm{ng} / \mathrm{mL})$ for $48 \mathrm{~h}$. The cell images were obtained under a light microscope $(\times 200)$.

producing Argl which competes with iNOS for the same substrate, arginine, thus decreasing NO generation [29]. We further investigated whether GA regulates NO production in BMDMs. As shown in Figure 5(a), iNOS and Arg1 gene products were reciprocally regulated by the GA treatment, as follows: iNOS mRNA expression induced by GA was detectable by $3 \mathrm{~h}$ and increased to its peak at $6 \mathrm{~h}$, whereas Argl mRNA was decreased by GA from basal levels to $30.64 \%$ of control at $24 \mathrm{~h}$. As anticipated, we also observed that GA obviously enhanced iNOS protein expression in BMDMs in a dose-dependent manner (Figure 5(b)), and accordingly, the $\mathrm{NO}$ generation of GA-treated groups was significantly higher than those in the control groups (Figure 5(c)). In summary, these data supported the notion that GA could promote M1 macrophage polarization in BMDMs.

3.5. GA Enhances Phagocytosis and Bactericidal Capacity of BMDMs. Phagocytosis and bacterial killing play a crucial role in macrophage-mediated host defense, which lead to internalization and destruction of pathogens. To determine whether GA triggers such functions on M1-polarized BMDMs, we first examined the internalization of FITClabeled dextran by FACS. The BMDMs pretreated with GA for
$12 \mathrm{~h}$ showed markedly increased uptake of FITC-dextran as compared with the control groups (Figure 6(a)). To support these findings, we evaluated the effect of GA on the uptake of E. coli $\mathrm{K} 88$ and S. typhimurium by BMDMs. Interestingly, GA significantly increased the uptake of extracellular bacteria E. coli K88 as compared with the control groups, while the internalization of intracellular bacteria $S$. typhimurium had no significant difference between the GA-treated groups and the control groups (Figure 6(b)). These inconsistent results of E. coli K88 and S. typhimurium internalization by BMDMs may result from the mechanisms by which S. typhimurium efficiently invades macrophages. After bacteria internalization by BMDMs, we further examined the bactericidal capacity of macrophages. As shown in Figure 6(b), GA markedly reduced the bacterial survival both in E. coli K88 and S. typhimurium infection models, relative to the control groups, respectively. To sum up, these results demonstrated that GA could enhance the phagocytic and bactericidal capacity of BMDMs.

3.6. GA Activates MAPKs and NF- $\kappa B$ Pathways in BMDMs. Macrophage polarization is a complex process including stimuli recognition and activation of the transcription factors 

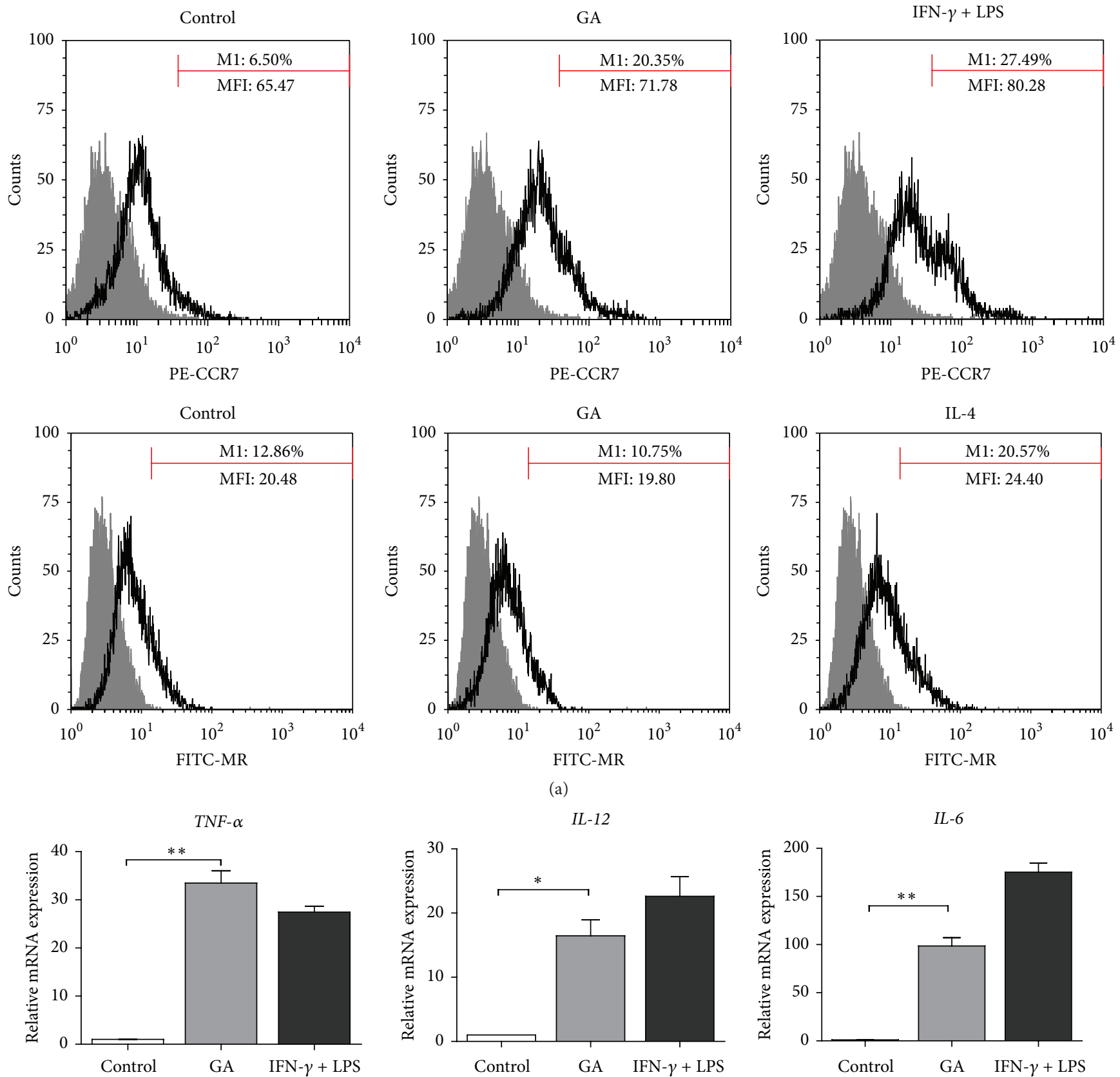

(a)
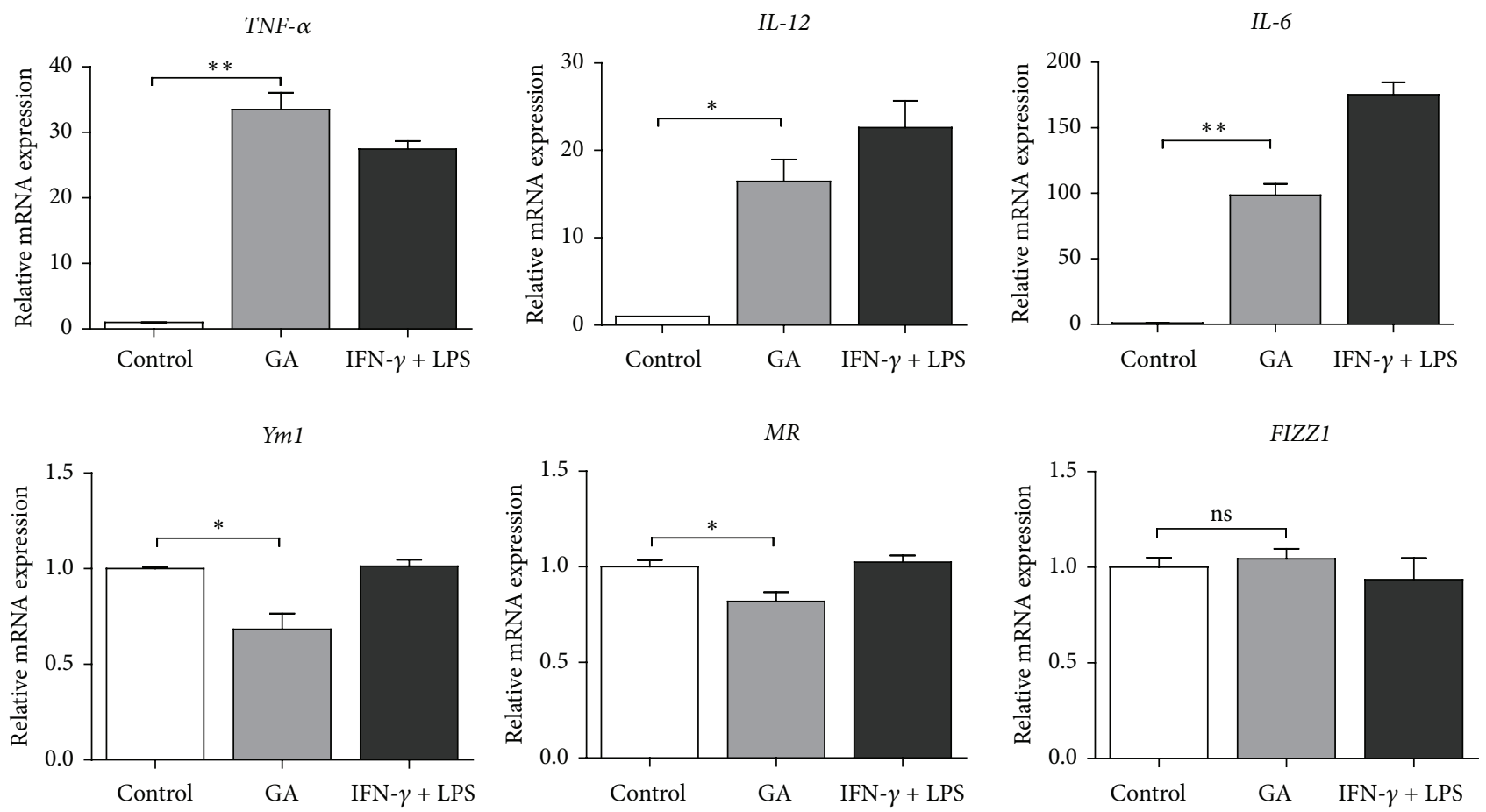

(b)

FIgUre 4: Continued. 
TNF- $\alpha$

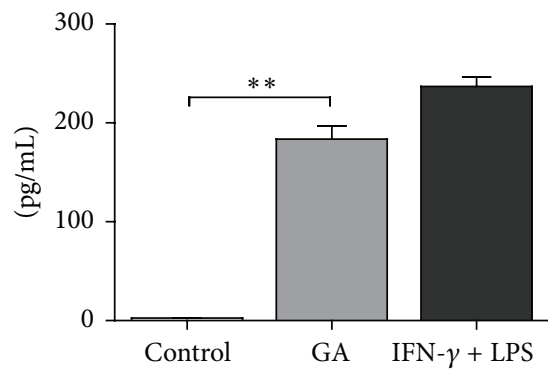

IL-12

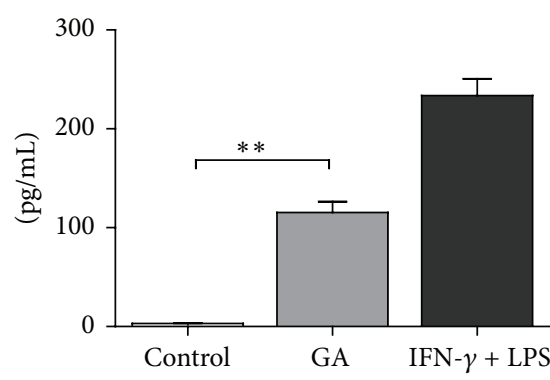

IL-6

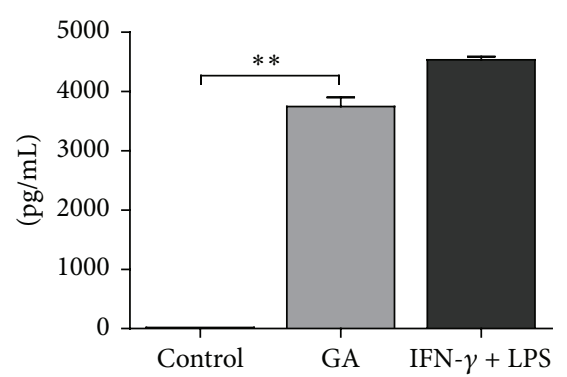

(c)

FIGURE 4: Effect of GA on M1- and M2-related markers expression in BMDMs. BMDMs were treated with GA (100 $\mu \mathrm{g} / \mathrm{mL})$ for $48 \mathrm{~h}$, the cells and supernatants were collected. (a) CCR7 and MR expressions were analyzed by FACS and (c) TNF- $\alpha$, IL-12, and IL-6 secretions were quantified by ELISA. (b) BMDMs were treated with GA $(100 \mu \mathrm{g} / \mathrm{mL})$ for $6 \mathrm{~h}$, total RNA was extracted, and TNF- $\alpha, I L-12, I L-6, Y m 1, M R$, and FIZZ1 expressions were measured by real-time PCR. Data are expressed as mean \pm SD from three independent experiments. ${ }^{*} P<0.05$, ${ }^{* *} P<0.01$ ( $t$-test).

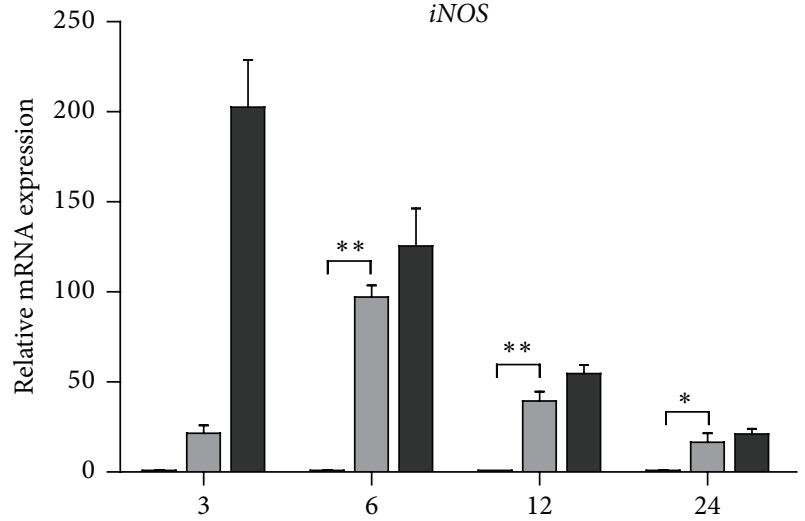

(h)

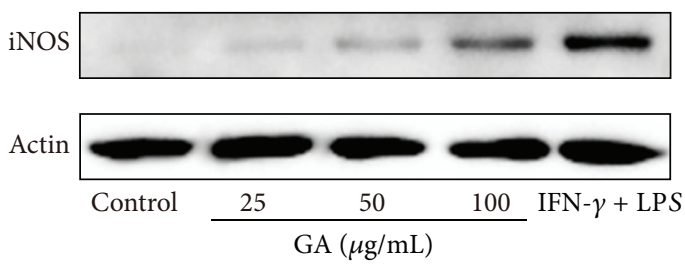

(b)

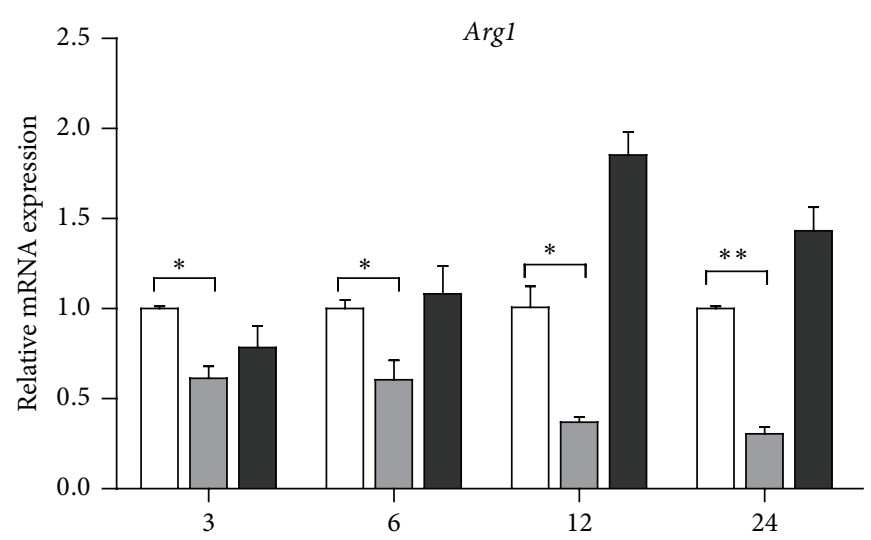

(h)

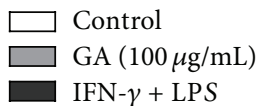

(a)

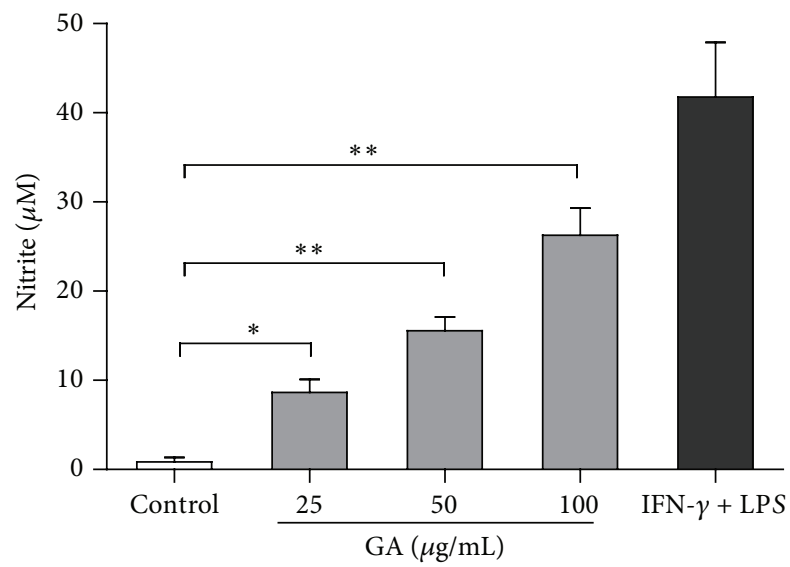

(c)

FIGURE 5: Effect of GA on NO synthesis in BMDMs. BMDMs were treated with GA $(25 \sim 100 \mu \mathrm{g} / \mathrm{mL})$. (a) At the indicated time points, total RNA was extracted and the expressions of $i N O S$ and Argl were measured by real-time PCR. (b, c) After 24 h of treatment, cells and supernatants were collected, cell lysates were prepared and subjected to western blotting with iNOS and $\beta$-actin antibody, and the nitrite generation in the supernatants was quantified as described in Section 2. Data are mean \pm SD for three independent experiments. ${ }^{*} P<0.05,{ }^{* *} P<0.01(t$-test). 

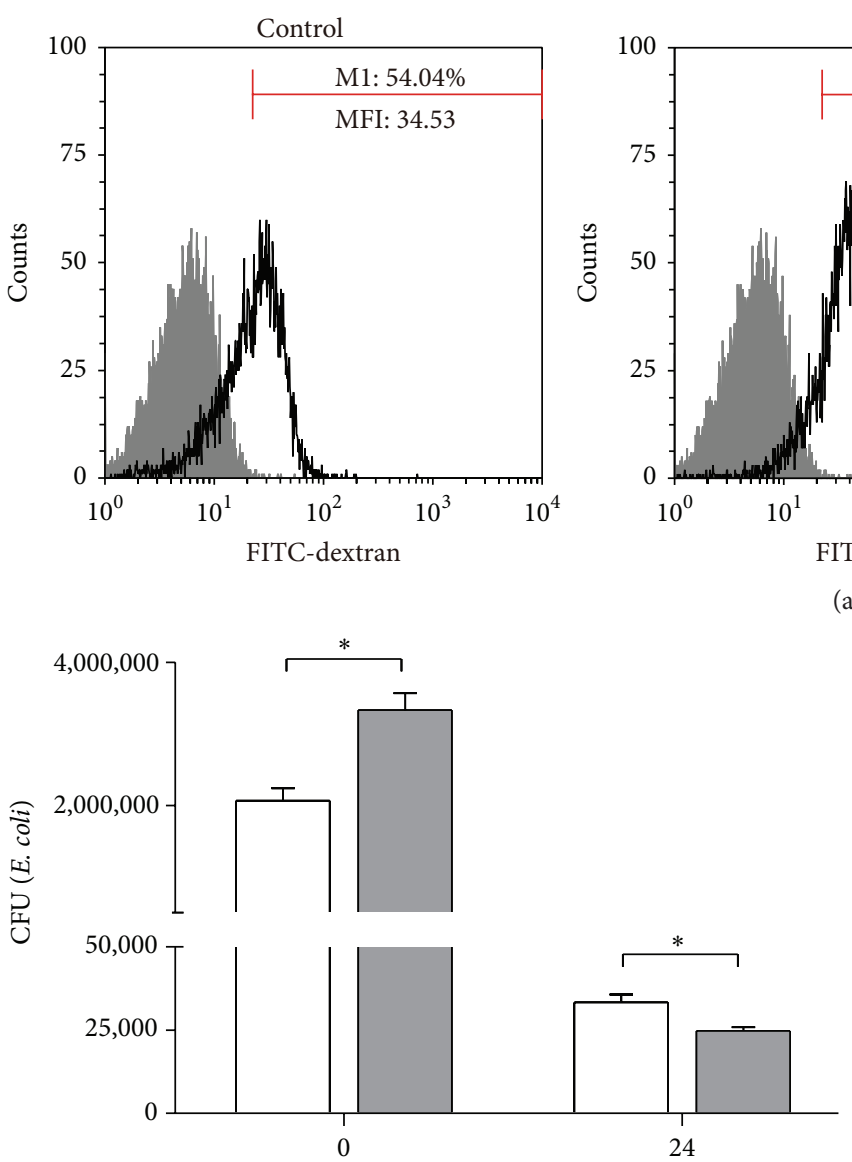

(h)

Control

GA

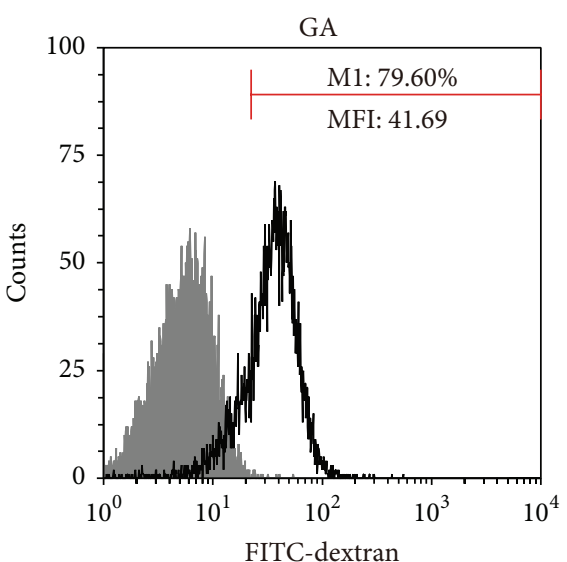

(a)

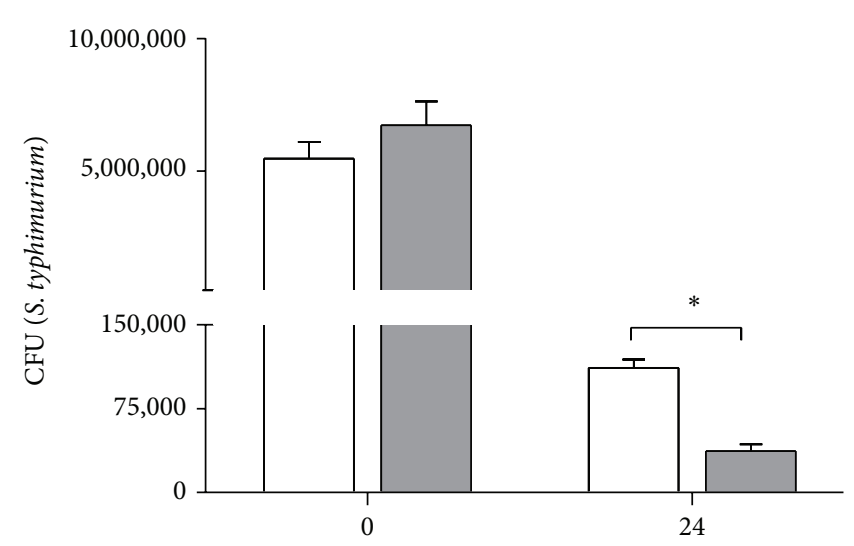

(h)

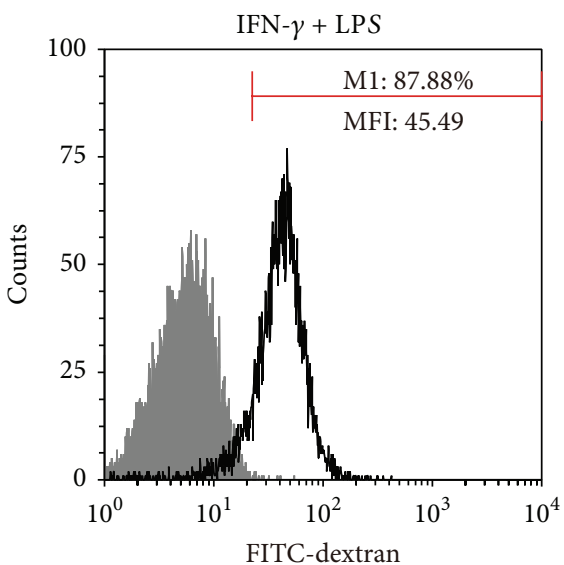

$\square$ Control
$\square$ GA

(b)

FIGURE 6: Effect of GA on BMDMs phagocytosis and bactericidal activity. BMDMs were pretreated with GA (100 $\mu \mathrm{g} / \mathrm{mL})$ for $12 \mathrm{~h}$. (a) Incubated with FITC-dextran at $37^{\circ} \mathrm{C}$ for $1 \mathrm{~h}$, the intracellular FITC-dextran was measured by FACS. (b) After being infected with E. coli K88 or S. typhimurium for $1 \mathrm{~h}$, washed, and incubated in DMEM with gentamicin $(25 \mu \mathrm{g} / \mathrm{mL})$ for $0 \mathrm{~h}$ or $24 \mathrm{~h}$, these cells were lysed, diluted, and plated on LB plates for colony enumeration. Data are mean \pm SD for three independent experiments. ${ }^{*} P<0.05(t$-test).

[30]. Recent studies have shown that MAPKs, NF- $\kappa$ B, and STAT1 signaling pathways are involved in M1 macrophage polarization [16, 31]. To investigate whether GA activates these cascades, we performed western blotting to examine the phosphorylation of MAPKs and STAT1 and the nuclear translocation of NF- $\kappa$ B p65. Treatment with GA led to a rapid and transient increase in the phosphorylated forms of all three MAPKs in BMDMs, and phosphorylation reached its peak at $30 \mathrm{~min}$ of treatment and declined to almost basal level within $60 \mathrm{~min}$ (Figure 7(a)). We also observed that GA triggered a gradual increase of NF- $\kappa \mathrm{B}$ p 65 protein in the nucleus, while it correspondingly decreased $\mathrm{I} \kappa \mathrm{B} \alpha$ protein in the cytosol within $60 \mathrm{~min}$ of stimulation (Figure 7(b)). However, GA did not induce phosphorylation of STAT1 in BMDMs (Figure 7(c)), indicating that GA-mediated M1 macrophage polarization was independent of STAT1 signaling.
3.7. GA-Induced M1 Macrophages Polarization Is Mediated by JNK and NF- $\kappa B$. We next determine the role of MAPKs and NF- $\kappa \mathrm{B}$ activation in GA-induced M1 macrophages polarization. BMDMs were, respectively, pretreated with pharmacological inhibitors for $30 \mathrm{~min}$ and then incubated with GA for $48 \mathrm{~h}$. As shown in Figure 7(d), Bay 11-0782 (NF$\kappa \mathrm{B}$ ) and SP600125 (JNK), but not SB203580 (p38 MAPK), significantly decreased GA-induced production of $\mathrm{NO}$ and M1-related cytokines (shown with IL-6 as an example), whereas pretreatment with U0126 (ERK1/2) resulted in unexpected increases in both $\mathrm{NO}$ and M1 cytokines production. Furthermore, inhibition of ERK1/2 pathway led to a marked decrease of IL-10 expression, at both the mRNA and protein levels (Figure 8). Together, these data thus indicated that NF- $\kappa \mathrm{B}$ and JNK activation are required for GA-induced M1 macrophages polarization, while ERK1/2 pathway exhibits a regulatory effect via induction of inhibitory factors, such as IL-10. 


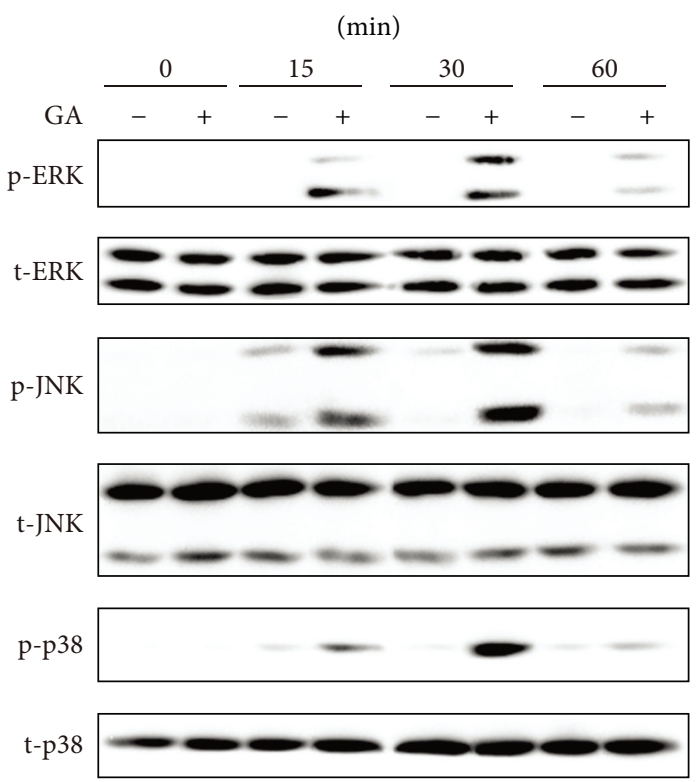

(a)

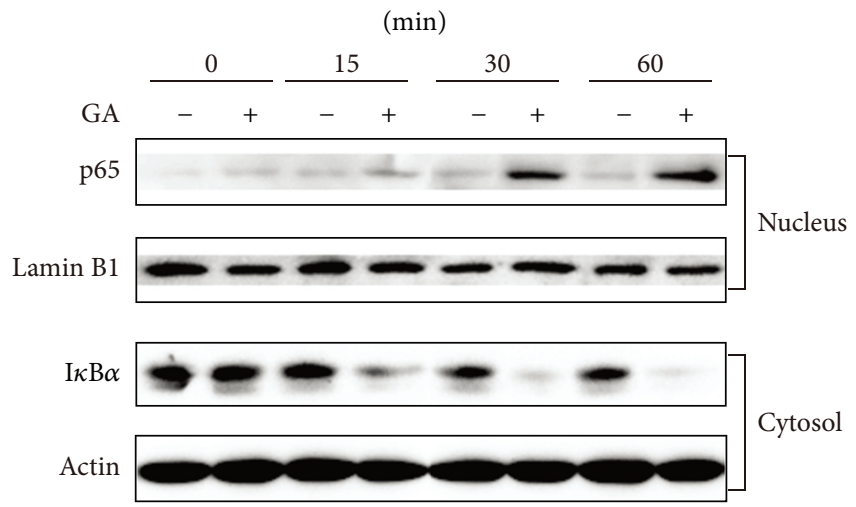

(b)

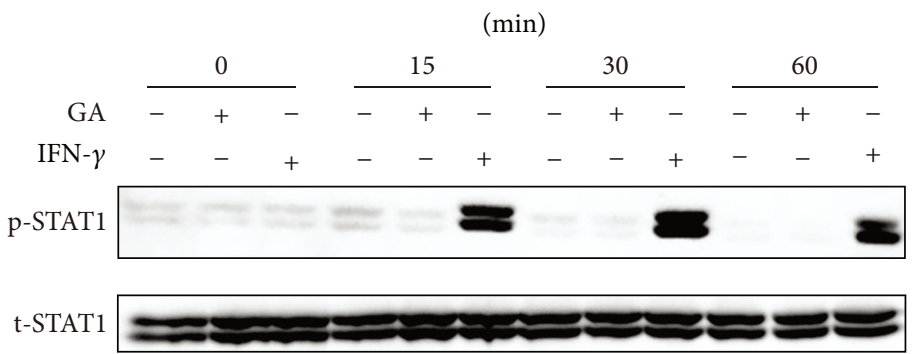

(c)
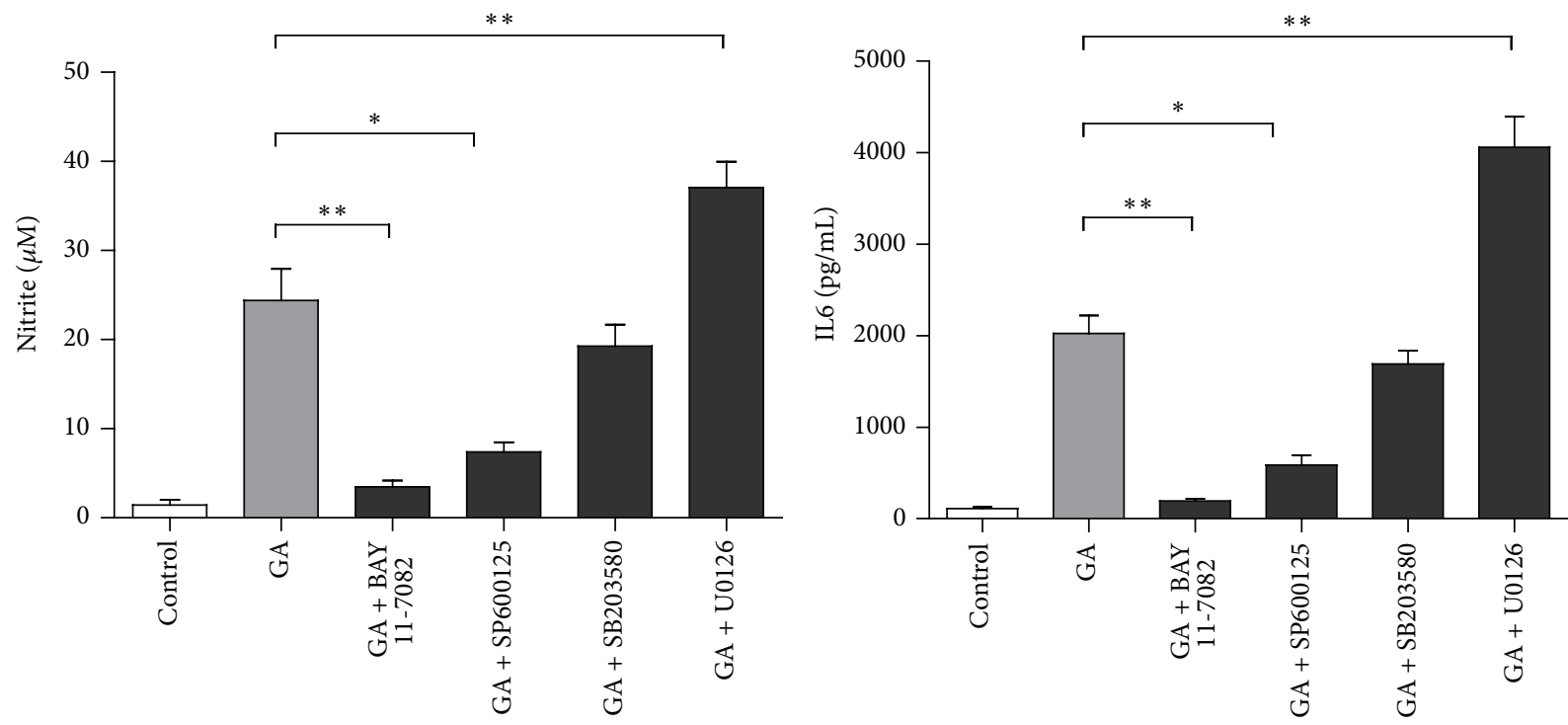

(d)

FIgURE 7: Effect of GA on MAPKs, NF- $\kappa$ B, and STAT1 activation in BMDMs. BMDMs were treated with GA (100 $\mu \mathrm{g} / \mathrm{mL})$ or IFN- $\gamma$ $(100 \mathrm{ng} / \mathrm{mL})$ for the indicated time points. (a, c) Cell lysates were prepared, and phosphorylation of ERK1/2 (p-ERK1/2), JNK (p-JNK), p38 MAPK (p-p38), and STAT1 (p-STAT1) was analyzed by western blotting. (b) Nuclear and cytosolic extracts were prepared and subjected to western blotting with p65 and $\mathrm{I} \kappa \mathrm{B} \alpha$ antibody, respectively. (d) BMDMs were pretreated with NF- $\kappa \mathrm{B}$ inhibitor (BAY 11-7082, 10 $\mu \mathrm{M})$, JNK inhibitor (SP600125, $10 \mu \mathrm{M}$ ), p38 MAPK inhibitor (SB203580, $10 \mu \mathrm{M})$, or ERK1/2 inhibitor (U0126, $10 \mu \mathrm{M})$ followed by treatment with GA $(100 \mu \mathrm{g} / \mathrm{mL})$ for $48 \mathrm{~h}$, and then the production of nitrite and M1-related cytokines was analyzed. Data are mean \pm SD for three independent experiments. ${ }^{*} P<0.05,{ }^{* *} P<0.01$ ( $t$-test). 


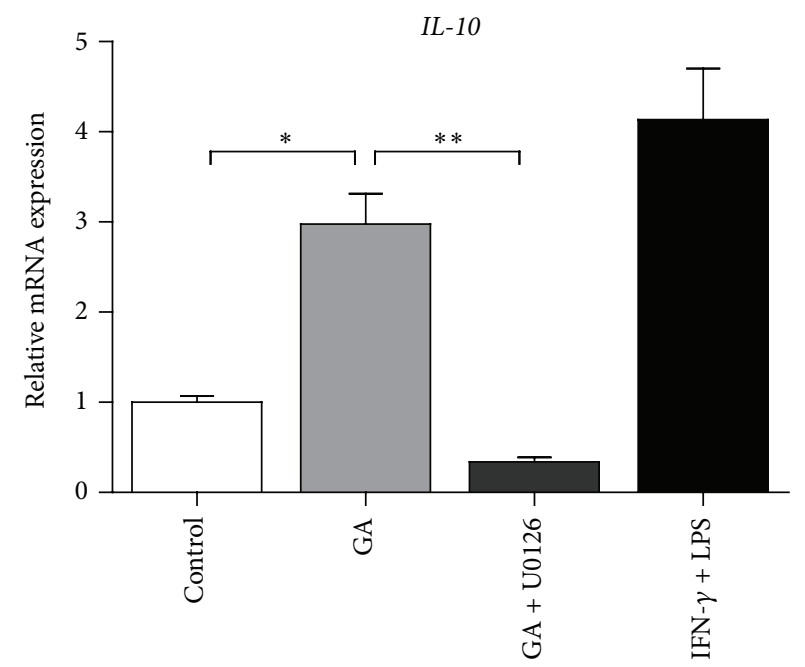

(a)

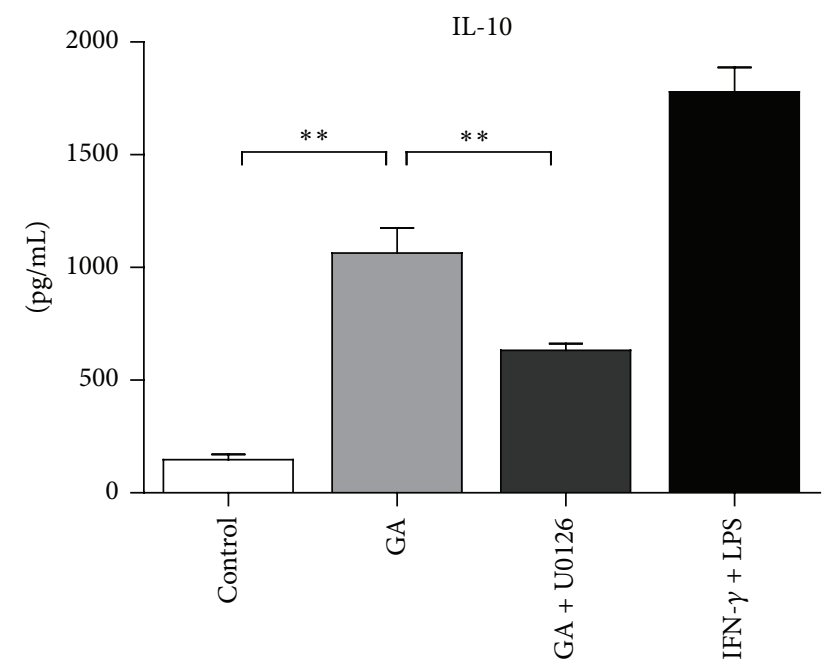

(b)

FIGURE 8: Effect of ERK1/2 pathway on GA-induced IL-10 production in M1-polarized BMDMs. BMDMs were pretreated with ERK1/2 inhibitor (U0126, $10 \mu \mathrm{M})$ followed by treatment with GA $(100 \mu \mathrm{g} / \mathrm{mL})$ for $(\mathrm{a}) 6 \mathrm{~h}$ or (b) $48 \mathrm{~h}$, and IL-10 mRNA expression and IL-10 secretion were measured by real-time PCR and ELISA, respectively. Data are mean \pm SD for three independent experiments. ${ }^{*} P<0.05,{ }^{* *} P<0.01$ ( $t$-test).

\section{Discussion}

Macrophages are an extremely heterogeneous lineage displaying a range of both pro- and anti-inflammatory functions. A functional phenotype obtained by macrophages is dependent upon interactions with specific stimuli from both endogenous and exogenous environment [17]. However, unlike T cells, which undergo extensive epigenetic modifications during differentiation, macrophages seem to retain their plasticity and respond to further environmental signals [16]. Previous studies observed that a phenotypic switch from M1 to M2 phenotype in the macrophage population occurs in the pathological process of cancer $[16,30]$. Moreover, some pathogens, such as Francisella tularensis and Leishmania major, are able to redirect the phenotype of macrophages from M1 to M2 and consequently survive at the expense of the host $[29,32]$. Therefore, targeting of this macrophage phenotypic plasticity may provide a novel therapeutic strategy for such diseases and infections.

Here, we investigated the effect of GA on the phenotypic polarization of macrophages. Our data showed that GA markedly increased the expression of CD80, CD86, and MHCII molecules, which associated with the antigen presentation and T lymphocyte activation. Similar results were obtained from GA-treated DCs that induced Th1 responses [10]. We further analyzed the expression of M1- and M2related markers in BMDMs and found that GA significantly upregulated the expression of CCR7, TNF- $\alpha$, IL12, and IL-6, which are related to M1 macrophages, whereas GA downregulated the expression of M2-related markers MR and Ym1. These results are in agreement with previous studies that GA exhibited a stimulatory effect on coronavirus and Leishmania donovani infected peritoneal macrophages via induction of proinflammatory effectors $[8,33]$.
The NO metabolism is an important distinction between M1 and M2 macrophages. M1 macrophages produce high levels of iNOS which synthesizes NO from arginine, while M2 macrophages counteract iNOS activity by producing Argl which degrades arginine to urea and ornithine, thus reducing the production of NO [29]. We observed that GA reciprocally regulated the expression of iNOS and Argl in BMDMs, which led to an increased production of NO. These results are supported by a report that GA enhanced NO production in IFN- $\gamma$-activated macrophages [14]. Moreover, M1 macrophages are known as potent effector cells with enhanced phagocytosis and bactericidal capacity [16]. Consistent with these notions, GA enhanced uptake of FITCdextran and E. coli K88 by BMDMs and markedly decreased the intracellular survival of E. coli K88 and S. typhimurium. To the best of our knowledge, there is no previous report on the bacterial killing capacity of GA-treated macrophages. Our data provide evidence that GA exhibits a protective effect in host defense against intracellular microorganisms by mediating the M1 functional polarization of macrophages.

Since a macrophage polarization requires activation of specific transcription factors, the possible pathways involved in GA-polarized M1 macrophages could be carefully identified. It is known that MAPKs (ERK, JNK, and p38 MAPK) regulate various inflammatory cytokines expression through phosphorylation of transcription factors. NF- $\kappa \mathrm{B}$ proteins are detached from its inhibitor $\mathrm{I} \kappa \mathrm{Bs}$ after activation and translocate from the cytoplasm to the nucleus and finally regulate the transcription of a large number of genes [34]. We found that GA induced phosphorylation of all three MAPKs, which was accompanied by nuclear translocation of $\mathrm{NF}-\kappa \mathrm{B}$ p 65 . Inhibition of JNK and NF- $\kappa \mathrm{B}$ activation by their respective inhibitors significantly decreased GA-induced production of NO and M1-related cytokines. Recent study 
demonstrated that JNK was required for M1 macrophage polarization in HFD-fed mice, and deficiency of JNK led to decreased expression of M1 genes and increased expression of M2 genes in adipose tissue macrophages [31]. In addition, NF- $\kappa$ B pathway was also reported to be associated with M1 macrophage polarization [16]. Inhibition of p38 MAPK did no effect on GA-induced M1 markers; however, inhibition of ERK1/2 resulted in unexpected increases in both $\mathrm{NO}$ and $\mathrm{M} 1$ cytokines production. ERK1/2 seems to be a regulator which limits inflammation via induction of anti-inflammatory cytokines [35]. We further confirmed that inhibition of ERK1/2 markedly decreased GA-induced IL10 expression in BMDMs. To sum up, JNK and NF- $\kappa \mathrm{B}$ activation are required for GA-induced M1 macrophages polarization, while ERK1/2 pathway exhibits a regulatory effect in prevention of excessive inflammation.

It should also be noted that some studies reported that GA inhibited the induction of proinflammatory effectors induced by TLR (toll-like receptor) agonists (e.g., CpG-DNA and LPS). In fact, the anti-inflammatory activity of GA may result from the changes in cell membrane, thus attenuating membrane-dependent receptor signaling. For instance, GA decreased cellular attachment or uptake of CpG-DNA and strongly impaired LPS-induced homodimerization of TLR4 in RAW 264.7 cells $[16,36,37]$. Here, we demonstrated that GA itself exhibits stimulatory effect, rather than inhibitory effect on BMDMs by skewing the M1 macrophage polarization bias.

It is still unclear how macrophages recognize GA, but the interaction between GA and cell membrane has been observed [36-38]. Our data showed a clear relationship between GA and M1 macrophage polarization which is known to be important for the clearance of intracellular pathogens and tumor cells. As the phenotype of a macrophage population appears to be changed by specific stimuli [16], GA might be a useful therapeutic for M2-associated diseases or infections by converting the macrophage population from M2 to M1 phenotype. Hence, it would be interesting to further introduce in vivo and in vitro studies to explore the role of GA in M2-dominated models.

\section{Conclusion}

In conclusion, we demonstrated a novel role for GA in the polarization of M1 macrophage. These findings might give a new insight into the function of GA on immune system and highlight the clinical significance of GA as a positive modulator in response to pathogens invasion.

\section{Conflict of Interests}

The authors declare that there is no conflict of interests regarding the publication of this paper.

\section{Authors' Contribution}

Yulong Mao and Baikui Wang have contributed equally to this work.

\section{Acknowledgments}

This work was supported by the grants from the National Natural Science Foundation of China (518001-N11409). The authors thank all workers of the study for their participation.

\section{References}

[1] C. Fiore, M. Eisenhut, E. Ragazzi, G. Zanchin, and D. Armanini, "A history of the therapeutic use of liquorice in Europe," Journal of Ethnopharmacology, vol. 99, no. 3, pp. 317-324, 2005.

[2] M. N. Asl and H. Hosseinzadeh, "Review of pharmacological effects of Glycyrrhiza sp. and its bioactive compounds," Phytotherapy Research, vol. 22, no. 6, pp. 709-724, 2008.

[3] V. I. Litvinenko and G. V. Obolentseva, "Chemical and pharmaceutical research on flavanoids of glycyrrhiza glabra 1. and glycyrrhiza uralensis fisch," Meditsinskaia Promyshlennost' SSSR, vol. 18, pp. 20-23, 1964.

[4] S. Matsui, H. Matsumoto, Y. Sonoda et al., "Glycyrrhizin and related compounds down-regulate production of inflammatory chemokines IL-8 and eotaxin 1 in a human lung fibroblast cell line," International Immunopharmacology, vol. 4, no. 13, pp. 1633-1644, 2004.

[5] L. Badam, "In vitro antiviral activity of indigenous glycyrrhizin, licorice and glycyrrhizic acid (Sigma) on Japanese encephalitis virus," The Journal of Communicable Diseases, vol. 29, no. 2, pp. 91-99, 1997.

[6] H. Sato, W. Goto, J.-I. Yamamura et al., "Therapeutic basis of glycyrrhizin on chronic hepatitis B," Antiviral Research, vol. 30, no. 2-3, pp. 171-177, 1996.

[7] C.-Y. Wang, T.-C. Kao, W.-H. Lo, and G.-C. Yen, "Glycyrrhizic acid and $18 \beta$-glycyrrhetinic acid modulate lipopolysaccharideinduced inflammatory response by suppression of NF- $\kappa \mathrm{B}$ through PI3K p110 $\delta$ and p110 $\gamma$ inhibitions," Journal of Agricultural and Food Chemistry, vol. 59, no. 14, pp. 7726-7733, 2011.

[8] S. Bhattacharjee, A. Bhattacharjee, S. Majumder, S. B. Majumdar, and S. Majumdar, "Glycyrrhizic acid suppresses cox2-mediated anti-inflammatory responses during Leishmania donovani infection," The Journal of Antimicrobial Chemotherapy, vol. 67, no. 8, pp. 1905-1914, 2012.

[9] H. Hua, Z. Liang, W. Li et al., "Phenotypic and functional maturation of murine dendritic cells (DCs) induced by purified Glycyrrhizin (GL)," International Immunopharmacology, vol. 12, no. 3, pp. 518-525, 2012.

[10] N. Bordbar, M. H. Karimi, and Z. Amirghofran, "The effect of glycyrrhizin on maturation and $\mathrm{T}$ cell stimulating activity of dendritic cells," Cellular Immunology, vol. 280, no. 1, pp. 44-49, 2012.

[11] Y. H. Zhang, K. Isobe, F. Nagase et al., "Glycyrrhizin as a promoter of the late signal transduction for interleukin-2 production by splenic lymphocytes," Immunology, vol. 79, no. 4, pp. 528-534, 1993.

[12] N. Abe, T. Ebina, and N. Ishida, "Interferon induction by glycyrrhizin and glycyrrhetinic acid in mice," Microbiology and Immunology, vol. 26, no. 6, pp. 535-539, 1982.

[13] K. Itoh and K. Kumagai, "Augmentation of NK activity by several anti-inflammatory agents," Excerpta Medica, vol. 641, pp. 460-464, 1983.

[14] H. Yi, I. Nakashima, and K.-I. Isobe, "Enhancement of nitric oxide production from activated macrophages by glycyrrhizin," The American Journal of Chinese Medicine, vol. 24, no. 3-4, pp. 271-278, 1996. 
[15] M. Naito, "Macrophage differentiation and function in health and disease," Pathology International, vol. 58, no. 3, pp. 143-155, 2008.

[16] D. M. Mosser and J. P. Edwards, "Exploring the full spectrum of macrophage activation," Nature Reviews Immunology, vol. 8, no. 12, pp. 958-969, 2008.

[17] S. Gordon, "Alternative activation of macrophages," Nature Reviews Immunology, vol. 3, no. 1, pp. 23-35, 2003.

[18] D. M. Mosser, "The many faces of macrophage activation," Journal of Leukocyte Biology, vol. 73, no. 2, pp. 209-212, 2003.

[19] B. N. Brown, R. Londono, S. Tottey et al., "Macrophage phenotype as a predictor of constructive remodeling following the implantation of biologically derived surgical mesh materials," Acta Biomaterialia, vol. 8, no. 3, pp. 978-987, 2012.

[20] H. Qin, A. T. Holdbrooks, Y. Liu, S. L. Reynolds, L. L. Yanagisawa, and E. N. Benveniste, "SOCS3 deficiency promotes M1 macrophage polarization and inflammation," The Journal of Immunology, vol. 189, no. 7, pp. 3439-3448, 2012.

[21] A. Mantovani and M. Locati, "Orchestration of macrophage polarization," Blood, vol. 114, no. 15, pp. 3135-3136, 2009.

[22] T. Satoh, O. Takeuchi, A. Vandenbon et al., "The Jmjd3-Irf4 axis regulates M2 macrophage polarization and host responses against helminth infection," Nature Immunology, vol. 11, no. 10, pp. 936-944, 2010.

[23] E. L. Racoosin and J. A. Swanson, "Macrophage colonystimulating factor (rM-CSF) stimulates pinocytosis in bone marrow-derived macrophages," The Journal of Experimental Medicine, vol. 170, no. 5, pp. 1635-1648, 1989.

[24] T. Mosmann, "Rapid colorimetric assay for cellular growth and survival: application to proliferation and cytotoxicity assays," Journal of Immunological Methods, vol. 65, no. 1-2, pp. 55-63, 1983.

[25] J. Y. Koh and D. W. Choi, "Quantitative determination of glutamate mediated cortical neuronal injury in cell culture by lactate dehydrogenase efflux assay," Journal of Neuroscience Methods, vol. 20, no. 1, pp. 83-90, 1987.

[26] S. Majumdar, L. H. Kane, M. W. Rossi, B. D. Volpp, W. M. Nauseef, and H. M. Korchak, "Protein kinase C isotypes and signal-transduction in human neutrophils: selective substrate specificity of calcium-dependent beta-PKC and novel calciumindependent nPKC," Biochimica et Biophysica Acta-Molecular Cell Research, vol. 1176, no. 3, pp. 276-286, 1993.

[27] Z. Zhang, Z.-Y. Zhang, and H. J. Schluesener, "Compound A, a plant origin ligand of glucocorticoid receptors, increases regulatory T cells and M2 macrophages to attenuate experimental autoimmune neuritis with reduced side effects," The Journal of Immunology, vol. 183, no. 5, pp. 3081-3091, 2009.

[28] T. Krausgruber, K. Blazek, T. Smallie et al., "IRF5 promotes inflammatory macrophage polarization and $\mathrm{T}_{H} 1-\mathrm{T}_{H} 17$ responses," Nature Immunology, vol. 12, no. 3, pp. 231-238, 2011.

[29] K. A. Shirey, L. E. Cole, A. D. Keegan, and S. N. Vogel, "Francisella tularensis live vaccine strain induces macrophage alternative activation as a survival mechanism," Journal of Immunology, vol. 181, no. 6, pp. 4159-4167, 2008.

[30] S. K. Biswas and A. Mantovani, "Macrophage plasticity and interaction with lymphocyte subsets: cancer as a paradigm," Nature Immunology, vol. 11, no. 10, pp. 889-896, 2010.

[31] M. S. Han, D. Y. Jung, C. Morel et al., "JNK expression by macrophages promotes obesity-induced insulin resistance and inflammation," Science, vol. 339, no. 6116, pp. 218-222, 2013.
[32] C. Hölscher, B. Arendse, A. Schwegmann, E. Myburgh, and F. Brombacher, "Impairment of alternative macrophage activation delays cutaneous leishmaniasis in nonhealing BALB/c mice," Journal of Immunology, vol. 176, no. 2, pp. 1115-1121, 2006.

[33] J. Cinatl, B. Morgenstern, G. Bauer, P. Chandra, H. Rabenau, and H. W. Doerr, "Glycyrrhizin, an active component of liquorice roots, and replication of SARS-associated coronavirus," The Lancet, vol. 361, no. 9374, pp. 2045-2046, 2003.

[34] Q. Li and I. M. Verma, "NF- $\kappa$ B regulation in the immune system," Nature Reviews Immunology, vol. 2, no. 10, pp. 725-734, 2002.

[35] M. Lucas, X. Zhang, V. Prasanna, and D. M. Mosser, "ERK activation following macrophage $\mathrm{F} c \gamma \mathrm{R}$ ligation leads to chromatin modifications at the IL-10 locus," The Journal of Immunology, vol. 175, no. 1, pp. 469-477, 2005.

[36] H. Honda, Y. Nagai, T. Matsunaga et al., "Glycyrrhizin and isoliquiritigenin suppress the LPS sensor Toll-like receptor 4/MD-2 complex signaling in a different manner," Journal of Leukocyte Biology, vol. 91, no. 6, pp. 967-976, 2012.

[37] S. Harada, "The broad anti-viral agent glycyrrhizin directly modulates the fluidity of plasma membrane and HIV-1 envelope," The Biochemical Journal, vol. 392, no. 1, pp. 191-199, 2005.

[38] B. Schröfelbauer, J. Raffetseder, M. Hauner, A. Wolkerstorfer, W. Ernst, and O. H. J. Szolar, "Glycyrrhizin, the main active compound in liquorice, attenuates pro-inflammatory responses by interfering with membrane-dependent receptor signalling," The Biochemical Journal, vol. 421, no. 3, pp. 473-482, 2009. 


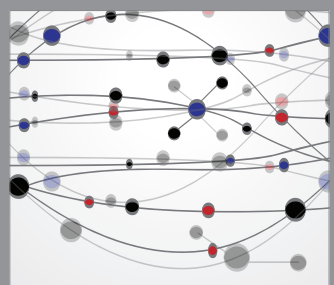

The Scientific World Journal
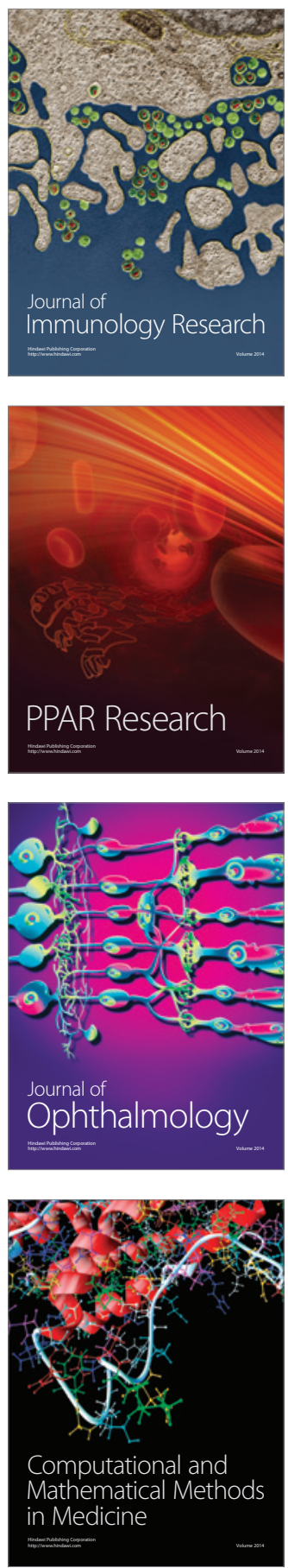

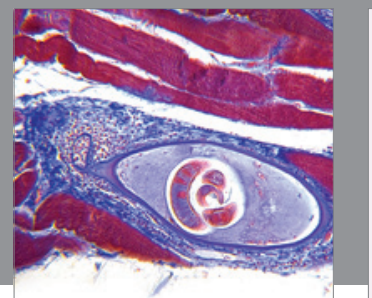

Gastroenterology

Research and Practice
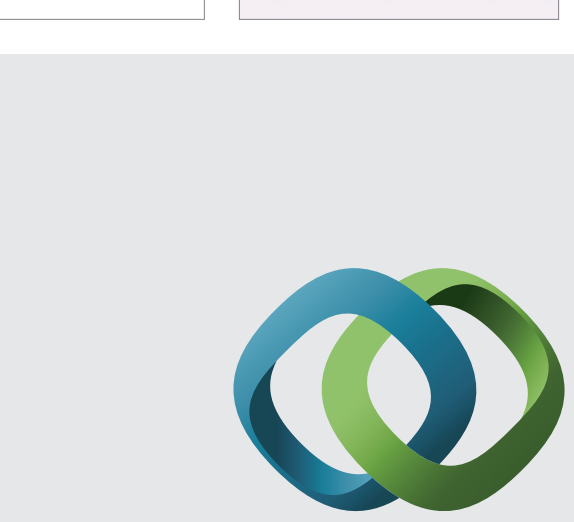

\section{Hindawi}

Submit your manuscripts at

http://www.hindawi.com
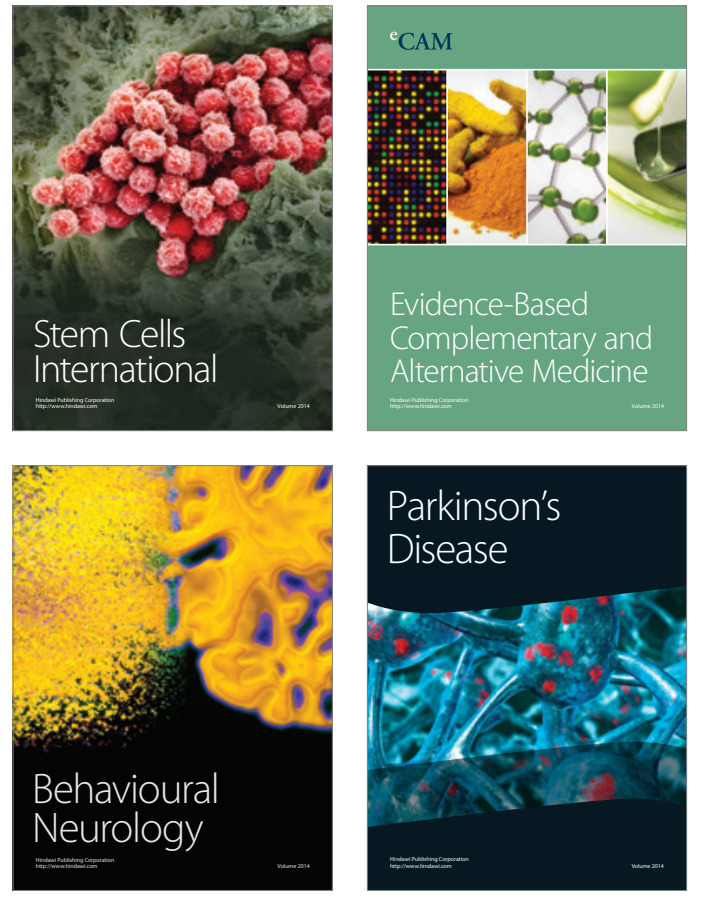
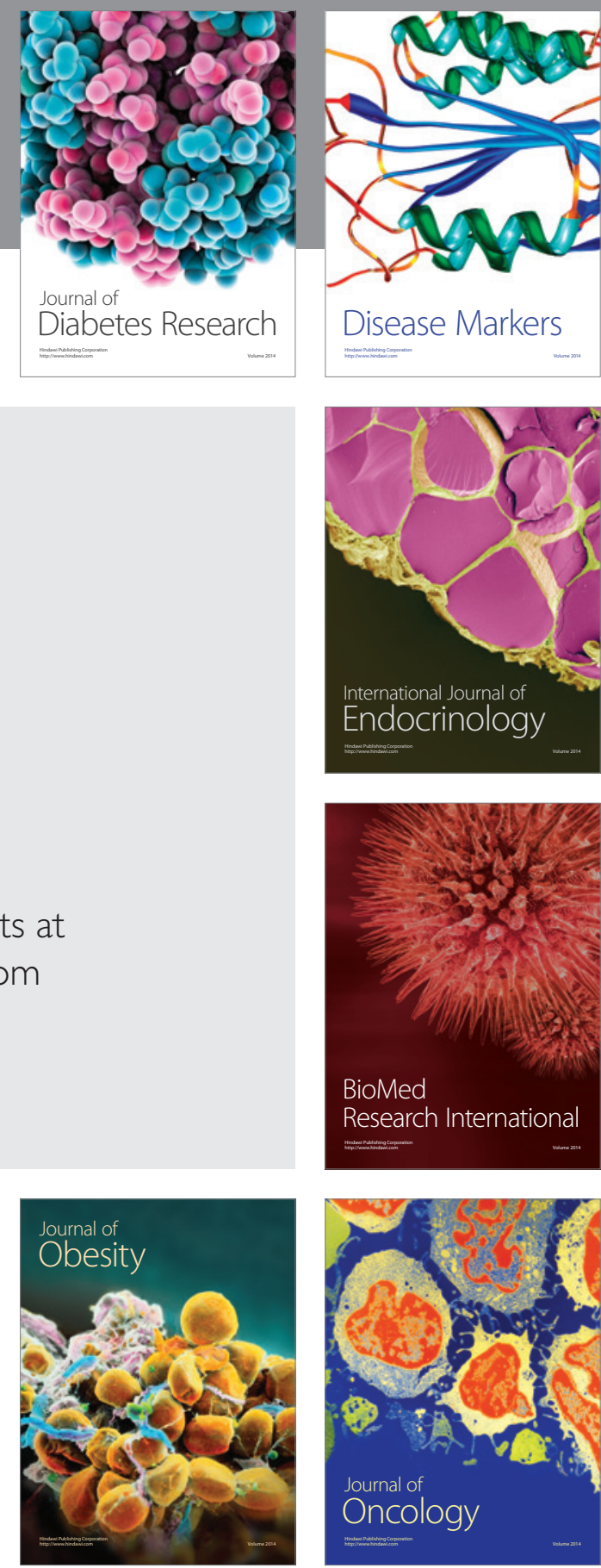

Disease Markers
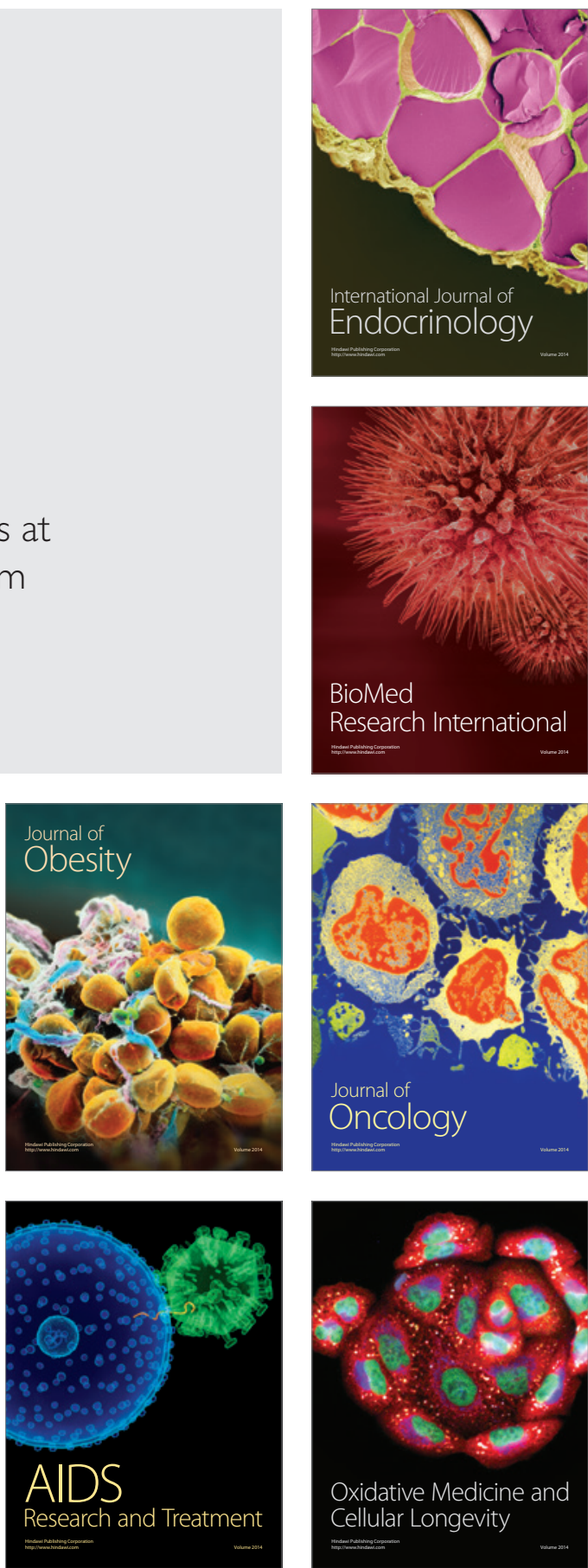